\title{
Ballistic Application of Coir Fiber Reinforced Epoxy Composite in Multilayered Armor
}

\author{
Fernanda Santos da Luz ${ }^{a *}$, Sergio Neves Monteiro ${ }^{a}$, Eduardo Sousa Lima ${ }^{a}$, Édio Pereira Lima Júnior ${ }^{a}$ \\ ${ }^{a}$ Military Institute of Engineering - IME, Department of Materials Science, Praça General Tibúrcio, 80, \\ Praia Vermelha, Urca, RJ, CEP 22290-270, Urca, Rio de Janeiro, RJ, Brazil
}

Received: December 08, 2016; Revised: February 21, 2017; Accepted: April 05, 2017.

\begin{abstract}
Multilayered armor systems (MAS) composed of relatively lighter materials with capacity to provide personal ballistic protection are being extensively investigated and used in armor vests. A typical MAS to stand high impact energy $7.62 \mathrm{~mm}$ bullet has a front ceramic followed by an aramid fabric laminate, such as Kevlar ${ }^{\mathrm{TM}}$. Since both the army and municipal police personnel might need to wear an armor vest, a large number of vests needs to be supplied. In the case of Kevlar ${ }^{\mathrm{TM}}$, one of the most expensive MAS material with an expiration time of 5 years, the possibility of its replacement by an equally ballistic efficient low cost material and more durable could be a relevant economical advantage. Natural fibers composites have recently been investigated as possible alternatives for Kevlar ${ }^{\mathrm{TM}}$. In particular, the fiber extracted from the coconut fruit, known as coir fiber, normally disposed as waste, could be a low cost material for this purpose. Therefore, the present work investigated the possibility of using coir fiber mantle, with different volume fraction, reinforcing epoxy composites as MAS second layer. It was found that $30 \mathrm{vol} \%$ of coir fiber composite displayed similar ballistic performance as compared to Kevlar ${ }^{\mathrm{TM}}$ with substantial economical advantage.
\end{abstract}

Keywords: Multilayered armor, Coir fiber, Epoxy composite, Ballistic performance

\section{Introduction}

The escalating armed conflicts in both large urban municipalities and conflagrated regions around the world, is motivating the development of more powerful fire arms and corresponding efficient armors. Not only single material but also multilayered materials armors are used today depending on the power of the fire arm ammunition. A multilayered armor system (MAS) provides protection against high impact velocity projectile such as the caliber $7.62 \mathrm{~mm}$. A typical MAS is basically composed of a front ceramic layer with the main purpose of absorbing most of the projectiles high impact energy. This is accomplished through the projectile rupture and erosion as well as by dynamic fragmentation of the ceramic ${ }^{1-5}$. The front ceramic is followed by a lower density second layer, normally a polymeric material, with the aim of further reducing the remaining impact energy associated with a cloud of fragments generated from the shattering of the ceramic and projectile.

The synthetic polymeric materials traditionally employed as MAS second layer, especially in vests for personal protection, are the aramid fabric laminate, commercially available as Kevlar ${ }^{\mathrm{TM}}$ from Dupont ${ }^{6,7}$ or the ultra high molecular weight polyethylene (UHMWPE), commercially available as Dyneema ${ }^{\mathrm{TM}}$ from $\mathrm{DSM}^{8,9}$. Although the ballistic performance for individual safety is the major seek requirement in the development of MAS, cost might also be an important factor. Therefore, new materials are

* e-mail: fsl.santos@gmail.com being investigated to attend both ballistic performance and economical market advantage. Polymer based composites reinforced with natural fibers have been ballistic tested as possible application in armors ${ }^{10-16}$. Recently the use of natural fabrics, fabricated from lignocellulosic fibers, as polymer composite reinforcement to be applied in MAS second layer was investigated ${ }^{17,18}$. In addition to much lower cost in comparison to synthetic aramid or UHMWPE fibers, natural fibers and fabrics are sustainable and neutral with respect to $\mathrm{CO}_{2}$ emission responsible for global warming ${ }^{19-23}$. However a synthetic fiber like Kevlar ${ }^{\mathrm{TM}} 49$, with a tensile strength of $3800-4200 \mathrm{MPa}^{24}$, is much stronger than natural fibers that barely reach $1000 \mathrm{MPa}^{19}$. This is even more significant in the case of the fiber extracted from the mesocarp of the green coconut fruit, also known as coir fiber. The tensile strength of the coir fiber is only $95-220 \mathrm{MPa}^{19}$ but polymer composites reinforced with coir fibers have recently been investigated ${ }^{25}$ and already applied, including as automobile parts ${ }^{26}$.

The reader may question whether a much weaker coir fiber reinforcing a composite with also relatively weak matrix like epoxy, 28-90 $\mathrm{MPa}^{24}$, could replace Kevlar ${ }^{\mathrm{TM}}$ as MAS second layer. The present work will show that this is possible because the mechanism of impact energy dissipation by a second layer does not depend on the fiber strength but on its capacity to capture fragments coming from the shatter of the front ceramic layer ${ }^{27}$. This may be efficiently done by the coir fiber composites. Another advantage of the coir fiber is that coconuts are abundant in several developing tropical countries like Brazil. Table 1 presents the Brazilian production 
from 2006 to 2015 of some crops associated with natural fibers. It should be noted that coconuts stands only behind cotton. Today around $30 \%$ of this production occur in the northeast part of the country ${ }^{28}$ and the commercial interest is for the liquid and meal inside the coconut fruit. The husk corresponding to $85 \mathrm{wt} \%$ of the fruit, where coir fibers are extracted, is generally considered garbage to be disposed. Only in last decades, a small fraction of coir fibers in Brazil is being considered for industrial applications. Nevertheless, investigations on new applications for coir fiber are growing owing to its very low cost, low density, great availability and relatively high resistance to ambient degradation due to the fiber high lignin content ${ }^{25}$.

In the present work the ballistic performance of MASs using coir fiber mantle, Figure 1, reinforced epoxy composites, as second layer, was for the first time compared to similar MAS with second layer of Kevlar ${ }^{\mathrm{TM}}$ with same thickness. This novel comparison was based on the NIJ standard ${ }^{29}$ that considers a maximum penetration of $44 \mathrm{~mm}$ inside a block of clay witness, which simulates a human body, place behind the MAS in the ballistic test. Different volume fractions of the coir fiber mantle, Fig. 1b, reinforcing epoxy composites were investigated as MAS second layer against class III $^{29}$ high impact power $7.62 \mathrm{~mm}$ ammunition.

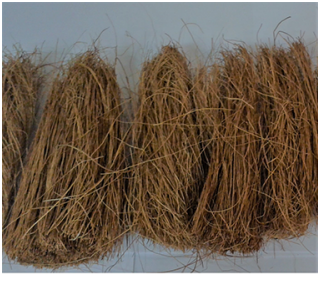

(a) Coir fibers

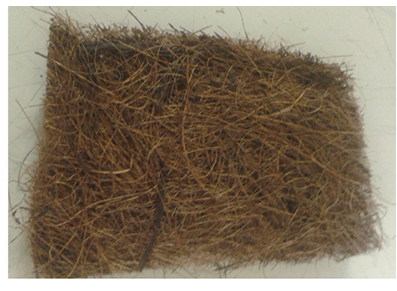

(b) Coir fiber mantle
Figure 1. Coir fibers extracted from the mesocarp in the husk of a green coconut fruit (a) and coir fiber mantle (b).

\section{Materials and Methods}

The materials used in this work were basically a laboratory fabricated tile of front ceramic and plates of coir fiber mantlereinforced epoxy composite as MAS second layer. A sheet of 5052-H34 aluminum alloy with 120x150 mm of lateral dimensions and $5 \mathrm{~mm}$ of thickness, used as MAS third layer, was supplied by the Metalak firm.
The hexagonal ceramic tile with side dimensions of $31 \mathrm{~mm}$ and $10 \mathrm{~mm}$ in thickness was fabricated with $\mathrm{Al}_{2} \mathrm{O}_{3}$ powder supplied by Treibacher Schleifmittle do Brasil and $\mathrm{Nb}_{2} \mathrm{O}_{5}$ powder supplied by the Companhia Brasileira de Metalurgia e Mineração (CBMM). These two powders were mixed with polyethyleneglycol (PEG), supplied by the Vetec Química Fina, as an organic bonding. The mixture was comminuted in a model MA500 Marconi ball mill for 8 hours using $94.53 \mathrm{wt} \% \mathrm{Al}_{2} \mathrm{O}_{3}, 3.94 \mathrm{wt} \% \mathrm{Nb}_{2} \mathrm{O}_{5}$ and $1.53 \mathrm{wt} \%$ PEG. It was then sintered at $1400^{\circ} \mathrm{C}$ for 3 hours, resulting in grain size of $4 \mu \mathrm{m}$.

The sintered $\mathrm{Al}_{2} \mathrm{O}_{3}-4.0 \mathrm{wt} \% \mathrm{Nb}_{2} \mathrm{O}_{5}$ presented intergranular precipitates that favor a complete brittle fracture upon ballistic impact. This efficiently dissipates energy by fragmentation into small pieces with size comparable to that of the grains. Figure 2 illustrates schematically the typical MAS used in this work with a second layer of epoxy composite reinforced with 10,20 and $30 \mathrm{vol} \%$ of coir fiber mantle.

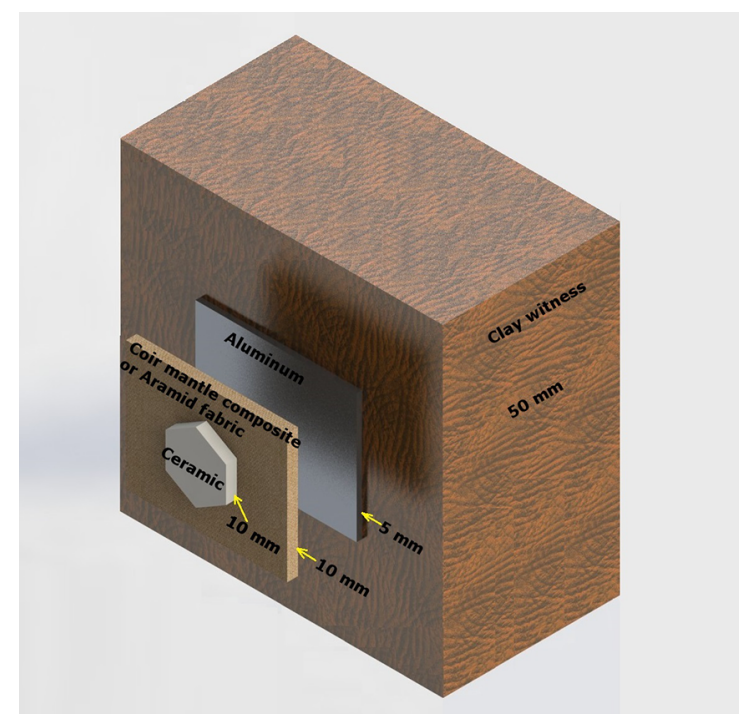

Figure 2. Schematic of the MAS placed in front of a block of clay witness simulating a human body.

Composite plates with lateral sides of $120 \times 150 \mathrm{~mm}$ and thickness of $10 \mathrm{~mm}$ were fabricated with both coir fiber mantle supplied by the Coco Verde firm, Brazil, and epoxy resin type diglycidyl ether of bisphenol A(DGEBA) hardener with

Table 1. Brazilian crop of natural fiber containing products from 2006 to $2015^{28}$.

\begin{tabular}{lcccccccccc}
\hline \multicolumn{10}{c}{ Crop (1000 ton) } \\
\hline Product & 2006 & 2007 & 2008 & 2009 & 2010 & 2011 & 2012 & 2013 & 2014 & 2015 \\
Pineapple* & $1,707.1$ & $1,784.2$ & $1,712.4$ & $1,471.0$ & $1,470.4$ & $1,577.0$ & $1,697.7$ & $1,655.9$ & $1,762.9$ & $1,773.3$ \\
Cotton & 2,8987 & $4,110.8$ & $3,983.2$ & $2,897.5$ & $2,949.9$ & $5,070.7$ & $4,969.1$ & $3,417.2$ & $4,236.8$ & $4,096.9$ \\
Coconut* & $1,985.5$ & $1,887.3$ & $2,149.3$ & $1,973.4$ & $1,895.6$ & $1,962.4$ & $1,954.4$ & $1,926.9$ & $1,946.1$ & $1,833.4$ \\
Jute & 6.1 & 6.4 & 0.8 & 0.8 & 0.9 & 1.1 & 1.0 & 0.5 & 1.2 & 2.0 \\
Mallow & 19.9 & 19.3 & 12.6 & 14.1 & 13.2 & 15.6 & 8.5 & 9.5 & 8.1 & 4.8 \\
Sisal & 248.1 & 245.4 & 246.2 & 280.0 & 246.5 & 283.8 & 89.1 & 150.6 & 138.0 & 179.6 \\
\hline
\end{tabular}

* Crop of 1000 fruits. 
triethylenetetramine (TETA) produced by Dow Chemical and supplied by the firm Resinpoxy. Pieces of coir fiber mantle with $5 \mathrm{~mm}$ in thickness were placed inside a steel mold with dimensions corresponding to those of the final composite. The DGEBA/TETA fluid epoxy with stoichiometric phr 13 amount of hardener was poured onto the mantle pieces to fabricate laminate composites. After the necessary amount of mantle and epoxy, for a final $10 \mathrm{~mm}$ thick plate, the mold was closed and a load of 5 ton (pressure of $\sim 3 \mathrm{MPa}$ ) was applied for 24 hours. Figure 3 (a) shows a typical plate of $30 \mathrm{vol} \%$ coir fiber mantle epoxy composite.

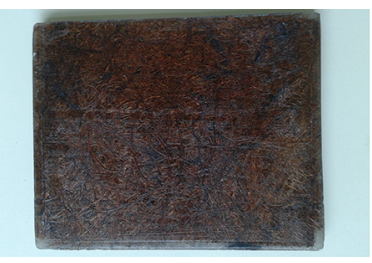

(a) Typial 30 vol\% fiber coir nantle cpoxy composite

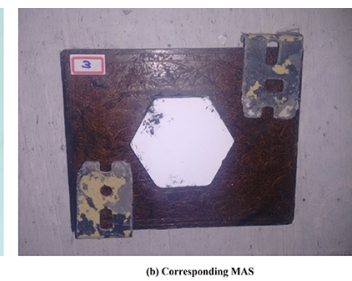

(b) Corresponding MAS
Figure 3. Typical 30 vol\% fiber coir mantle epoxy composite (a) and the corresponding MAS (b).

For the assembly of the MAS three layers, a Sikaflex ${ }^{\mathrm{TM}}$ adhesive, supplied by Sika firm, was used to bind the ceramic tile, composite plate and aluminum sheet together. Figure 3 (b) shows a complete MAS clamped to a clay witness block, supplied by the firm Corfix ${ }^{\mathrm{TM}}$, and ready to be ballistic tested.

Ballistic tests were carried out in the Centro de Avaliações do Exército (CAEx) located at the Marambaia peninsula in Rio de Janeiro, Brazil. Figure 4 shows schematically the arrangement for ballistic test in a CAEx sound proof tunnel. A gun barrel shoots the bullet, which goes through optical barriers and a model SL-52 OP Weibel fixed-head Doppler radar for velocity measurement. The MAS target is placed $15 \mathrm{~m}$ from the gun and the bullet trajectory, shown schematically in Fig. 4 as a dashed straight line, is sighted on the target center with a red laser beam. Spring clamps are used to hold in place the MAS target in direct contact with the clay witness block, which is mounted in a rigid steel frame. All ballistic tests were conducted according to the NIJ 0101.06 Standard ${ }^{29}$ using class III 7.62x51 mm NATO military ammunition ( $7.62 \mathrm{~mm}$ for short) with a $9.7 \mathrm{~g}$ lead bullet. After the ballistic test, samples of the fractured MAS layers were analyzed by Scanning Electron Microscopy (SEM) in a model Quanta FEG 250 Fei equipment operating with secondary electrons at $15 \mathrm{kV}$.

The evaluation of the ballistic performance of the MAS was based on the depth of indentation caused in the clay witness, matching the plastic deformation of the aluminum MAS third layer. This deformation corresponds to the last remaining impact energy dissipated by the MAS. The indentation measurement was performed by means of a model Q4X Banner laser sensor, as illustrated in Figure 5. A minimum of 12 indentation depths was measured, Fig 5 , in

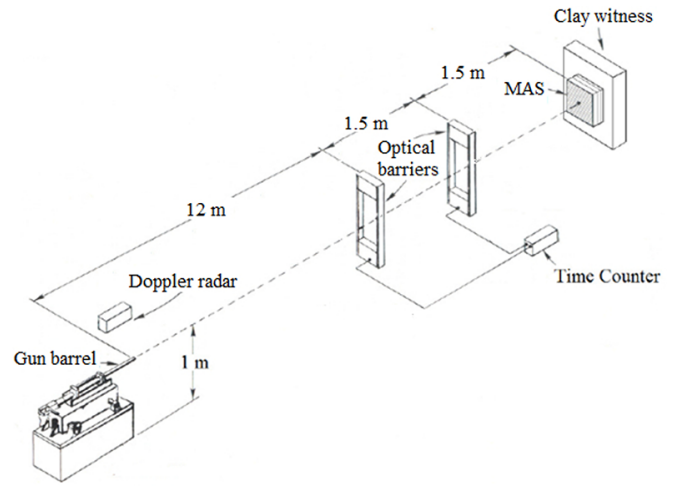

Figure 4. Schematic view of the ballistic test arrangement ${ }^{17}$ (adapted).

each ballistic test and the values were statistically analyzed by the Weibull method, briefly described in Appendix.

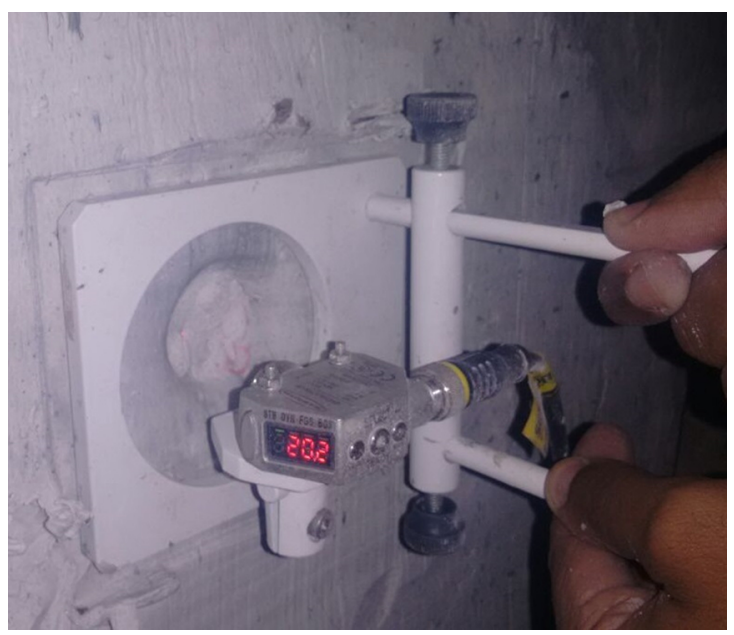

Figure 5. Measurement of the depth of indentation in the clay witness due to the remaining energy from the ballistic test 7.62 mm bullet impact against MAS.

\section{Results}

The Weibull statistic analysis of depth of indentation measurements revealed that all values for the investigated coir fiber mantle, 10, 20 and $30 \mathrm{vol} \%$, reinforced epoxy composites (coir mantle composites for short) as MAS second layer, Fig. 2 and 3, attended the standard ${ }^{29}$. Moreover, these depth of indentations were comparable to that of MAS using Kevlar ${ }^{\mathrm{TM}}$ as second layer. Table 2 presents the depth of indentation for MASs with coir mantle composites as second layers as well as corresponding values for Kevlar ${ }^{\mathrm{TM}}$ ${ }^{17}$ and pure epoxy ${ }^{13}$.

In this table one should notice that all depth indentation values are smaller than $44 \mathrm{~mm}$, which is the limit required by the standard ${ }^{29}$. As aforementioned, within the statistical precision, all these values are comparable. In other words, the corresponding MASs reveal similar ballistic performance against a $7.62 \mathrm{~mm}$ threat, including the MAS with Kevlar ${ }^{\mathrm{TM}}$. 
Table 2. Depth of indentation for MAS with different second layers ballistic tested against $7.62 \mathrm{~mm}$ bullet.

\begin{tabular}{lc}
\hline MAS second layer & Average depth of indentation $(\mathrm{mm})$ \\
\hline Kevlar $^{\mathrm{TM}}[16]$ & $23 \pm 3$ \\
$100 \%$ epoxy [12] & $20 \pm 1$ \\
$10 \%$ coir mantle/epoxy & $21 \pm 2$ \\
$20 \%$ coir mantle/epoxy & $22 \pm 2$ \\
$30 \%$ coir mantle/epoxy & $24 \pm 6$ \\
\hline
\end{tabular}

Figure 6 illustrates the aspect of MASs targets of Kevlar ${ }^{\mathrm{TM}}$ and coir mantle composites as second layers after ballistic tests. In this figure the front ceramic is almost completely gone destroyed due to intergranular fragmentation caused by the $\mathrm{Nb}_{2} \mathrm{O}_{5}$ embrittlement. Using Kevlar ${ }^{\mathrm{TM}}$ as MAS second layer, it was previously reported ${ }^{27}$ intergranular fragmentation is responsible for absorption of more than $50 \%$ of the impact energy.

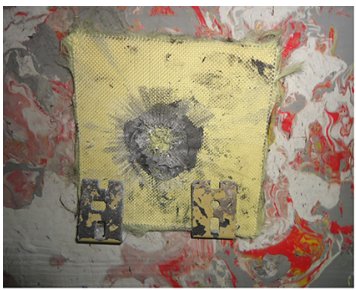

(a) Keviar'⿳亠口冋

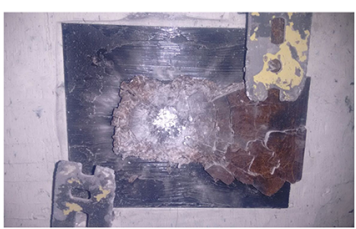

(c) $20 \%$ coir mantle reinfored epoxy composite

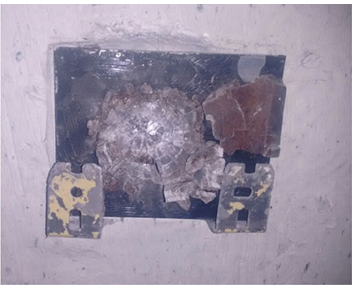

(b) $10 \%$ coir mantle reinforced epoxy composite

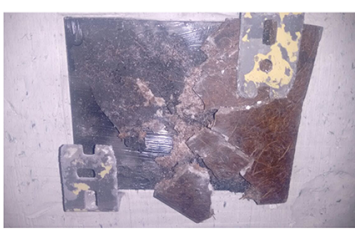

(d) $30 \%$ eoir mantle reinforced epory composite
Figure 6. Aspect of MASs with different second layers after ballistic test against $7.62 \mathrm{~mm}$ bullet: (a) Kevlar ${ }^{\mathrm{TM}}$; (b) 10\% coir mantle; (c) $20 \%$ coir mantle; and (d) $30 \%$ coir mantle reinforced epoxy composite.

Figure 7 shows the fractured surface of a $30 \mathrm{vol} \%$ coir mantle composite. In this figure one can clearly see broken coir fibers with internal fibrilar microstructure and lumen. Around these coir fibers extends the fractured brittle epoxy matrix. The brittle rupture of the epoxy matrix is another source of impact energy dissipation, which occurs by rapid nucleation and propagation of cracks $^{30}$. It is also important to notice in Fig. 7(a) the small white particles of ceramic covering the fracture surface. This is an indication of a mechanism associated with the capture of fragments from the front ceramic, as previously reported for other natural fiber composites as MAS second layer ${ }^{13-18}$. Evidence of coir fiber pullout is depicted in Fig 7 (b).

Table 3 presents a comparative economical analysis involving cost and weight of different MASs. Based on the data in Table one sees that a MAS with coir mantle
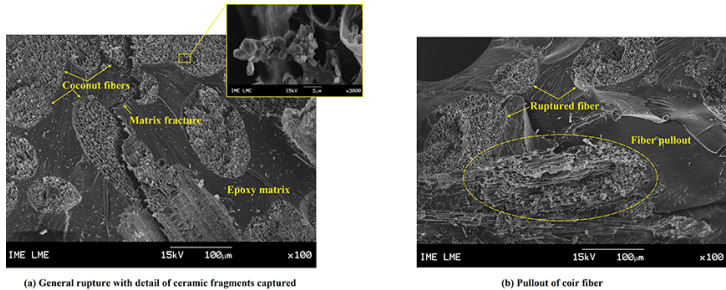

Figure 7. SEM fracture of a MAS with second layer of $30 \mathrm{vol} \%$ coir mantles-reinforced epoxy composite: (a) general rupture with detail of ceramic fragments captured and (b) pullout of coir fiber.

composite displays a reduction of $34 \%$ in total cost and $0.2 \%$ in weight as compared with a similar MAS (same thickness) with Kevlar ${ }^{\mathrm{TM}}$.

\section{Discussion}

The similar ballistic performance results in Table 2 can be attributed to distinct mechanisms of impact energy dissipation by the second layer, following the majority amount of energy dissipated by the front ceramic. In principle, the recognized mechanisms are stretching, delamination and rupture of fibers ${ }^{13-18}$. However, another efficient mechanism of energy dissipation is the capture of fragments resulting from the shatter of the first layer ${ }^{27}$.

Although all investigated MAS with coir mantle composites attended the depth of indentation criterion required by the standard ${ }^{29}$, none of the investigated composites kept its integrity after the ballistic impact. In Fig. 6, it was revealed the typical appearance of MASs after ballistic test. In this figure, one should notice that in all MASs the front ceramic was totally disintegrated. However, the Kevlar ${ }^{\mathrm{TM}}$ as second layer, Fig. 6 (a), remained intact except for the bullet perforation. By contrast, the coir mantle composites (10, 20 and $30 \mathrm{vol} \%$ incorporation) were partially destroyed. As a consequence, coir mantle composites cannot be used as a MAS second layer large plate in a vest for ballistic protection against high power ammunition such as $7.62 \mathrm{~mm}$. Similar to the front ceramic, a coir mantle composite could only be used as smaller pieces composing a mosaic. In this case, according to the standard ${ }^{29}$ the vest might protect a sequence of 6 ballistic impacts separated by $5 \mathrm{~cm}$ of distance.

The results of ballistic test showed that coir mantle composites as MAS second layer are able to resist the first impact of a $7.62 \mathrm{~mm}$ projectile. However, their partial disintegration, Fig. 6 (b), (c) and (d) will not resist a second impact. Possible reasons are associated with their fracture mechanisms, Fig. 6 and 7, involving separation of micorfibrils in the coir fiber, delamination of the coir mantle and fiber pullout from the matrix. Consequently, the coir fibers in a mantle do not seem to provide a good reinforcement to the epoxy matrix. Thus, a coir mantle composite can only be used as MAS second layer, to provide personal ballistic protection, in the form of small pieces composing a mosaic together with ceramic front tile. In this way, the MAS might 
Table 3. Estimative of weight and cost of the different MAS components.

\begin{tabular}{|c|c|c|c|c|c|}
\hline Armor component & Volume $\left(\mathrm{cm}^{3}\right)$ & Density $\left(\mathrm{g} / \mathrm{cm}^{3}\right)$ & Weight (kgf) & Price (US\$ $/ \mathrm{kg}) *$ & $\begin{array}{l}\text { Component } \\
\text { cost (US\$) }\end{array}$ \\
\hline $\mathrm{Al}_{2} \mathrm{O}_{3}$ & 225 & 3.38 & 0.761 & 33.00 & 25.11 \\
\hline Aramida fabric $\left(\text { Kevlar }^{\mathrm{TM}} \mathrm{S} 745-\mathrm{k} 29\right)^{18}$ & 225 & 1.09 & 0.245 & 63.60 & 15.58 \\
\hline 30 vol\% coir mantle/epoxy composite & 225 & 1.08 & 0.243 & $16.75^{\mathrm{a}}$ & 4.07 \\
\hline 5052-H34 aluminium sheet & 112.5 & 2.70 & 0.304 & 11.24 & 3.42 \\
\hline Total weight with Kevlar ${ }^{\mathrm{TM}}$ (kgf) & 1.310 & \multicolumn{3}{|c|}{ Total cost with aramid fabric (US\$) } & 44.11 \\
\hline Total weight with coir composite (kgf) & 1.308 & \multicolumn{3}{|c|}{ Total cost with coir composite (US\$) } & 32.60 \\
\hline Percentage decrease $(\%)$ & 0.2 & \multicolumn{3}{|c|}{ Percentage decrease $(\%)$} & 35 \\
\hline
\end{tabular}

${ }^{a}$ [coir fiber mantle US\$ $0.38(30 \%)$; epoxy US\$ $16.37(70 \%)$ ]

* US\$ $1=\mathrm{R} \$ 3.42$

be able to stand multiple ballistic impact, as required by the standards ${ }^{29}$.

In spite of this shortcoming, the MAS using a coir mantle composite as second layer has a marked economical advantage as shown in Table 3 . The reader should remember that coir fibers are today still consider a trash to be disposed.

\section{Conclusions}

- Epoxy composites incorporated with different fractions - 10, 20 and $30 \mathrm{vol} \%$ - of coir mantle attended the standard for ballistic protection against high power $7.62 \mathrm{~mm}$ ammunition, as second layer of a multiple layered system (MAS) with a front ceramic tile.

- The ballistic performance of MASs with coir mantle composite was comparable to that of similar thickness MAS with Kevlar ${ }^{\mathrm{TM}}$ as second layer.

- The partial disintegration of the coir mantle composite plates after the MAS ballistic impact, limits their application to small mosaic pieces to stand against multiples shots of $7.62 \mathrm{~mm}$ projectiles.

- Despite this limitation, a MAS with coir fiber mantle as second layer is $0.2 \%$ lighter and $34 \%$ cheaper than the traditional MAS with Kevlar ${ }^{\mathrm{TM}}$ as second layer and same thickness.

\section{Acknowledgements}

The authors thank the support to this investigation by the Brazilian agencies: CNPq, FAPERJ and CAPES $31007015006 \mathrm{P} 4$ do PDS program. It is also acknowledged CAEx for the ballistic tests.

\section{References}

1. Louro LHL, Meyers MA. Effect of stress state and microstructural parameters on impact damage of alumina-based ceramics. Journal of Materials Science. 1989;24(7):2516-2532.
2. Anderson CE Jr, Morris BL. The ballistic performance of confined $\mathrm{Al}_{2} \mathrm{O}_{3}$ ceramic tiles. International Journal of Impact Engineering. 1992;12(2):167-187.

3. Shokrieh MM, Javadpour GH. Penetration analysis of a projectile in ceramic composite armor. Composite Structures. 2008;82(2):269-276.

4. Medvedovski E. Ballistic Performance of armour ceramics: Influence of design and structure: Part 1. Ceramics International. 2010;36(7):2103-2115.;

5. Medvedovski E. Ballistic Performance of armour ceramics: Influence of design and structure: Part 2. Ceramics International. 2010;36(7):2117-2127.

6. Lee YS, Wetzel ED, Wagner NJ. The ballistic impact characteristics of Kevlar ${ }^{\sqrt{ }}$ woven fabrics impregnated with a colloidal shear thickening fluid. Journal of Materials Science. 2003;38(13):2825-2833.

7. Cheeseman BA, Bogetti TA. Ballistic impact into fabric and compliant composite laminates. Composite Structures. 2003;61(1-2):161-173.

8. Lee BL, Song JW, Ward JE. Failure of Spectra ${ }^{\circledR}$ Polyethylene Fiber Reinforced Composites under Ballistic Impact Loading. Journal of Composite Materials. 1994;28(13):1202-1226.

9. Morye SS, Hine PJ, Duckett RA, Carr DJ, Ward IM. Modeling of the energy absorption of polymer composites upon ballistic impact. Composites Science and Technology. 2000;60(14):2631-2642.

10. Ali A, Shaker ZR, Khalina A, Sapuan SM. Development of Anti-Ballistic Board from Ramie Fiber. Polymer-Plastics Technology and Engineering. 2011;50(6):622-634.

11. Wambua P, Vangrimde B, Lomov S, Verpoest I. The response of natural fibre composites to ballistic impact by fragment simulating projectiles. Composite Structures. 2007;77(2):232-240.

12. Abidin MHZ, Mohamad MAH, Zaidi AMA, Mat WAW. Experimental Study on Ballistic Resistance of Sandwich Panel Protection Structure with Kenaf Foam as a Core Material against Small Arm Bullet. Applied Mechanics and Materials. 2013;315:612-615.

13. Cruz RB, Lima Jr. EP, Monteiro SN, Louro LHL. Giant Bamboo Fiber Reinforced Epoxy Composite in Multilayered Ballistic Armor. Materials Research. 2015;18(Suppl. 2):70-75. 
14. Monteiro SN, Louro LHL, Trindade W, Elias CN, Ferreira CL, Lima ES, et al. Natural Curaua Fiber-Reinforced Composites in Multilayered Ballistic Armor. Metallurgical and Materials Transactions A. 2015;46(10):4567-4577.

15. Rohen LA, Margem FM, Monteiro SN, Vieira CMF, Araujo BM, Lima ES. Ballistic Efficiency of an Individual Epoxy Composite Reinforced with Sisal Fibers in Multilayered Armor. Materials Research. 2015;18(Suppl. 2):55-62.

16. Monteiro SN, Braga FO, Lima EP, Louro LHL, Drelich JW. Promising curaua fiber-reinforced polyester composite for high-impact ballistic multilayered armor. Polymer Engineering \& Science. 2016. DOI: 10.1002/pen.24471.

17. Luz FS, Lima Jr. EP, Louro LHL, Monteiro SN. Ballistic Test of Multilayered Armor with Intermediate Epoxy Composite Reinforced with Jute Fabric. Materials Research. 2015;18(Suppl. 2):170-177.

18. Monteiro SN, Milanezi TL, Louro LHL, Lima Jr. EP, Braga FO, Gomes AV, et al. Novel ballistic ramie fabric composite competing with Kevlar ${ }^{\mathrm{TM}}$ fabric in multilayered armor. Materials \& Design. 2016;96:263-269.

19. Monteiro SN, Lopes FDP, Barbosa AP, Bevitori AB, Silva ILA, Costa LL. Natural Lignocellulosic Fibers as Engineering Materials - An Overview. Metallurgical and Materials Transactions A. 2011;42:2963.

20. Faruk O, Bledzki AK, Fink HP, Sain M. Biocomposites reinforced with natural fibers: 2000-2010. Progress in Polymer Science. 2012;37(11):1552-1596.

21. Thakur VK, Thakur MK, Gupta RK. Review: Raw Natural Fibers-Based Polymer Composites. International Journal of Polymer Analysis and Characterization. 2014;19(3):256-271.

22. Pappu A, Patil V, Jain S, Mahindrakar A, Hanque R, Thakur VK. Advances in industrial prospective cellulosic macromolecules enriched banana biofibre resources: A review. International Journal of Biological Macromolecules. 2015;79:449-458.
23. Güven O, Monteiro SN, Moura EAB, Drelich JW. Re-Emerging Field of Lignocellulosic Fiber - Polymer Composites and Ionizing Radiation Technology in their Formulation. Polymer Reviews. 2016;56(4):702-736.

24. Callister WD Jr., Rethwish DG. Materials Science and Engineering - An Introduction. 8 $^{\text {th }}$ ed. Hoboken: Wiley; 2010.

25. Jayavani S, Deka H, Varghese TO, Nayak SK. Recent development and future trends in coir fiber reinforced green polymer composites: Review and evaluation. Polymer Composites. 2016;37(11):3296-3309.

26. Holbery J, Houston D. Natural-fiber-reinforced polymer composites in automotive applications. JOM. 2006;58(11):80-86.

27. Monteiro SN, Lima Jr. EP, Louro LHL, Silva LC, Drelich JW. Unlocking Function of Aramid Fibers in Multilayered Ballistic Armor. Metallurgical and Materials Transactions A. 2015;46(1):37-40

28. Brasil. Instituto Brasileiro de Geografia e Estatística. Systematic Survey of Agricultural Production (in Portuguese). Rio de Janeiro: IBGE. 2016. Available from: http://www.ibge.gov.br/ home/estatistica/pesquisas/anos anteriores 2016.shtm. Access in: $14 / 4 / 2017$

29. National Institute of Justice. NIJ 0101.06: Ballistic resistance of body armor. Washington: National Institute of Justice; 2008.

30. Morgan RJ, O’Neal JE. Effect of epoxy monomer crystallization and cure conditions on physical structure, fracture topography, and mechanical response of polyamide-cured bisphenol-Adiglycidyl ether epoxies. Journal of Macromolecular Science, Part B. 1978;15(1):139-169.

\section{Supplementary material}

The following online material is available for this article: Weibull Statistic Method 